\title{
Geochemical behavior of redox sensitive lanthanides and actinides at colloids-water interfaces
}

\author{
REMI MARSAC ${ }^{1}$, NIDHU LAL BANIK ${ }^{2}$, JOHANNES \\ LUETZENKIRCHEN $^{3}$ AND MATHIEU PÉDROT ${ }^{4}$ \\ ${ }^{1}$ Géosciences Rennes - UMR CNRS 6118 \\ ${ }^{2}$ European Commission \\ ${ }^{4}$ Univ Rennes, CNRS, Géosciences Rennes, UMR 6118 \\ Presenting Author: remi.marsac@univ-rennes1.fr
}

${ }^{3} \mathrm{KIT}$

Actinides are contaminants of special concern given the severe threats they may cause to human health, ecosystems and environment. Furthermore, progresses in industry, agriculture/farming, medicine, etc. lead to the release of new or "emerging" contaminants such as lanthanides, also called rare earth elements (REE), whose negative effects on the environment, if not yet established, are to be suspected. Once released in the environment, actinides and REE strongly bind to natural colloids (e.g. clays, metal oxides) and can be transported by water over large distances. Prediction of the fate and transport of actinides and REE is even more challenging in the case of redox sensitive actinides $(\mathrm{U}, \mathrm{Np}, \mathrm{Pu})$ and lanthanides $(\mathrm{Ce})$ because the chemical behaviors of two distinct oxidation states drastically differ, including their interactions with colloids.

Currently, determination and prediction of the redox speciation of these elements is often not possible because of the lack of analytical tools or gaps in reaction databases for speciation calculations. Fortunately, (i) actinides and REE are fblock elements, whose (bio)(geo)chemical behavior is similar when occurring under the same oxidation state, and (ii) some actinides and REE are stable under a single oxidation state over a large range of redox conditions. In a series of articles, ${ }^{1-5}$ an approach was developed to predict the sorption and redox speciation of $\mathrm{Np}$ and $\mathrm{Pu}$ at clay colloids surfaces (illite and kaolinite) under various environmental conditions, which involved data of chemical analogues. The latter approach will be shown applicable to the $\mathrm{Ce}(\mathrm{III})-\mathrm{Ce}(\mathrm{IV})$ system at manganese oxide surface. The discussion will also be extended to other inorganic contaminants than actinides and lanthanides (e.g. As, $\mathrm{Cr}$ ) at iron oxides surfaces, with the hope to provide a valuable tool to predict the environmental fate of a large range of contaminants.

References

(1) Marsac et al. Chem. Geol. 2015, 400, 1-10.

(2) Marsac et al. Geochim. Cosmochim. Acta 2015, 152, 3951.

(3) Marsac et al. J. Colloid Interface Sci. 2017, 485, 59-64.

(4) Banik et al. Environ. Sci. Technol. 2016, 50 (4), 20922098.

(5) Banik et al. Geochim. Cosmochim. Acta 2017, 215, 421431. 